\title{
Konservasi Lekat Lahan Tanaman Pekarangan Di Dua Desa Kabupaten Bogor
}

\author{
Dody Priadi a* \\ ${ }^{a}$ Pusat Penelitian Bioteknologi LIPI. JL Raya Bogor Km 46, Cibinong 16911, Indonesia \\ *Email: d_priadi2002@yahoo.com \\ Diterima (received) 11 Juli 2018; disetujui (accepted) 31 Januari 2019; tersedia secara online (available online) 1 Februari 2019
}

\begin{abstract}
On-farm conservation study was carried out in two villages within Bogor regency (Jampang and Cisarua). Those villages represented lowland and upland area respectively. The objective of the study was to identify the diversity of plants species at family home gardens in those areas. Data was taken from 10 home gardens in each village. Primary data was collected by direct observation to the home gardens and interview with the householders, while the secondary data obtained from literature study. Data was analyzed using D and D method. Result showed that 57 plant species were conserved onfarm at the home gardens in Jampang and 58 plant species in Cisarua village. Fruit plant was dominant species in Jampang while in Cisarua was ornamental plants.
\end{abstract}

Keywords: on-farm conservation; plant genetic resources; plant diversity; home garden

\section{Pendahuluan}

Konseravsi lekat lahan atau on-farm conservation adalah suatu sistem pelestarian yang dilakukan oleh masyarakat dengan menanami lahannya dengan bermacam-macam tanaman (Sastrapradja et al, 1989 dan Sumiasri \& Kusmawan, 2001).

Keterkaitan antara konservasi lekat lahan dengan pekarangan adalah bahwa pekarangan merupakan salah satu lahan tempat membudidayakan beraneka ragam plasma nutfah terutama tanaman budidaya dan usaha-usaha lain seperti peternakan, perikanan yang sekaligus melestarikannya. Semakin banyak jenis plasma nutfah yang dibudidayakan maka pelestarian plasma nutfah semakin intensif. Definisi pekarangan menurut Danusastro (1976) adalah lahan yang berada di sekeliling rumah yang dihuni secara permanen, memiliki batas yang jelas, ditanami dengan berbagai jenis tanaman dan pemiliknya memiliki hubungan fungsional dengan rumah tempat tinggal tersebut, sedangkan Karyono (1981) mendefinisikan pekarangan adalah sebagai sebidang tanah yang berada disekitar rumah yang mempunyai batas-batas tertentu, ditanami dengan satu atau berbagai tumbuhan dan masih mempunyai hubungan fungsional dengan rumah yang bersangkutan. Di kabupaten Bogor jenis-jenis tumbuhan tersebar di daerah dataran rendah, sedang dan tinggi (Sumiasri, 1992). Pada umumnya tanaman yang dibudidayakan oleh petani atau penduduk setempat adalah untuk memenuhi kebutuhan hidupnya sehari-hari (Lakitan, 1995), oleh karena itu biasanya dipilih tanaman yang mempunyai nilai ekonomi (Sumiasri dan Priadi. 2003).

Penelitian ini difokuskan di lahan pekarangan, karena lahan tersebut merupakan salah satu lahan petani yang dikelola lebih intensif dengan menanami berbagai tanaman sehingga dengan demikian petani dianggap telah melakukan upaya pelestarian tanaman. Semakin banyak jenis-jenis tanaman yang dibudidayakan semakin banyak pula jenis tanaman yang dilestarikannya. Penelitian bertujuan untuk mengetahui keanekaragaman jenis tanaman yang dilestarikan secara lekat lahan oleh penduduk di lahan pertaniannya terutama di pekarangan. Hasil yang diperoleh diharapkan menjadi rinformasi untuk lembaga yang begerak di bidang keplasmanutfahan khususnya dan umumnya sebagai pengetahuan untuk masyarakat.

doi: https://doi.org/10.24843/blje.2019.v19.i01.p04

(C) 2019 by the authors; Content from this work may be used under the terms of the Creative Commons Attribution 3.0 licence. Any further distribution of this work must maintain attribution to the author(s) and the title of the work, journal citation and DOI. Published under licence by Udayana University, Indonesia. 


\section{Metode Penelitian}

Penelitian dilakukan di desa Jampang, Kecamatan Gunung Sindur Kabupaten Bogor yaitu suatu daerah yang tergolong dataran rendah $(40 \mathrm{~m} \mathrm{dpl})$ dengan topografi datar serta berjenis tanah latosol dan desa Cisarua, Kecamatan Cisarua Kabupaten Bogor yang tergolong ke daerah dataran tinggi ( $950 \mathrm{~m}$ dpl) dengan topografi berbukit yang jenis tanahnya juga latosol (Perkins, et al, 1986). Sampel diambil secara acak dari 10 kepala keluarga (KK) di setiap desa yang pada umumnya adalah laki-laki berumur 49-50 tahun dan yang bertanggung jawab terhadap pengelolaan lahan pekarangan berlatar belakang pendidikan minimal SLTP dan masih dalam usia produktif. Apabila dalam satu pekarangan ada 2 KK maka tidak diambil sebagai sampel, dan sampel hanya dipilih dari pekarangan yang mempunyai satu KK. Luasan pekarangan tidak seragam tergantung pada kepemilikan lahan, sehingga dipilih luasan lahan yang hampir sama. Tanaman pekarangan dikategorikan ke dalam jenis buah-buahan, hias, sayuran, bahan bangunan, industri, peneduh, bumbu dan pangan. Penelitian ini dilakukan mulai bulan Januari sampai dengan Juni tahun 2010.

Metode penelitian yang dilakukan adalah berdasarkan pengamatan langsung di lapangan dan wawancara dengan kepala keluarga pemilik pekarangan tersebut. Data sekunder diperoleh dari penelusuran pustaka. Analisis data dilakukan dengan metode Diagnosis and Design $\quad$ (D \& D) yang dikembangkan oleh Raintree (1987).
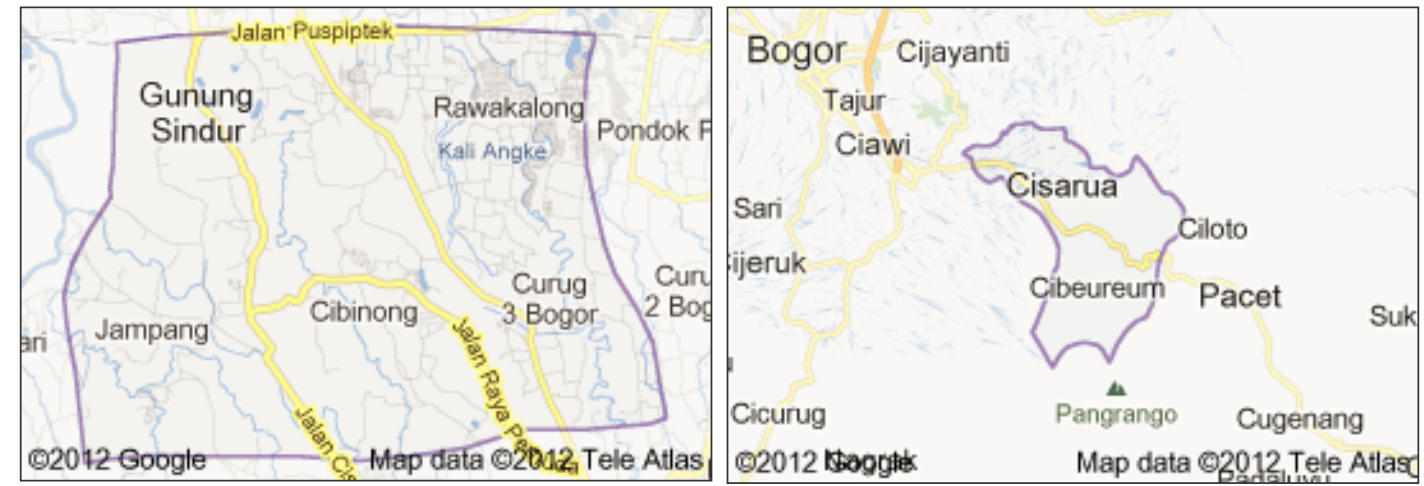

Gambar 1. Peta lokasi penelitian; (kiri) Jampang (dataran rendah), dan (kanan) Cisarua (dataran tinggi) (Sumber: Google Map data, 2012)

\section{Hasil dan Pembahasan}

\subsection{Hasil}

Hasil penelitian menunjukkan bahwa di desa Jampang terdapat 57 jenis tanaman yang dibudidayakan (Tabel 1). Contoh lahan pekarangan di desa Jampang ditunjukan pada Gambar 2.

Tabel 1. Jenis tanaman yang dibudidayakan di lahan petani di daerah dataran rendah desa Jampang, Bogor

\begin{tabular}{|r|l|l|}
\hline No & \multicolumn{1}{|c|}{ Nama Lokal } & \multicolumn{1}{c|}{ Nama ilmiah } \\
\hline 1. & Apokat & Persea americana \\
\hline 2. & Bambu cina & Bambusa aurea \\
\hline 3. & Bambu kuning & Bambusa vulgaris \\
\hline 4. & Belimbing & Averhoa carambola \\
\hline 5. & Benda & Artocarpus elastica \\
\hline 6. & Buni & Antidesma bunius \\
\hline 7. & Cabe kecil & Capsicum fructecens \\
\hline
\end{tabular}


D Priadi; Konservasi Lekat Lahan Tanaman Pekarangan Di Dua Desa Kabupaten Bogor..

\begin{tabular}{|c|c|c|}
\hline No & Nama Lokal & Nama ilmiah \\
\hline 8. & Calincing & Averrhoa bilimbi \\
\hline 9. & Cemara & Casuarina junghuniana \\
\hline 10. & Cempedak & Artocarpus champeden \\
\hline 11. & Duku & Lansium domesticum \\
\hline 12. & Durian & Durio zibethinus \\
\hline 13. & Euphorbia & Euhorbia bravoniana \\
\hline 14. & Flamboyan & Delonix regia \\
\hline 15. & Hanjuang & Cordyline fruticosa \\
\hline 16. & Jamblang & Eugenia cumini \\
\hline 17. & Jambu air & Zyzygium aqueum \\
\hline 18. & Jambu batu & Psidium guajava \\
\hline 19. & Jambu bol & Zyzygium malaccensis \\
\hline 20. & Jati & Tectona grandis \\
\hline 21. & Jengkol & Phitecellobium jiringa \\
\hline 22. & Jeruk besar & Citrus maxima \\
\hline 23. & Kapulasan & Nephelium mutabile \\
\hline 24. & Kelapa & Cocos nucifera \\
\hline 25. & Keluwih & Artocarpus communis \\
\hline 26. & Kemang & Mangifera caesia \\
\hline 27. & Kembang kertas merah & Bougenvilia spectabilis \\
\hline 28. & Kenikir & Cosmos caudatus \\
\hline 29. & Kersen & Muntingia calabura \\
\hline 30. & Kihujan & Samaea saman \\
\hline 31. & Lamtoro & Leucaena glauca \\
\hline 32. & Lengkuas & Zyzygium polyantum \\
\hline 33. & Langsat & Lansium domesticum \\
\hline 34. & Lengkeng & Euphoria longan \\
\hline 35. & Lidah mertua & Sanseviera malabarica \\
\hline 36. & Mangga & Mangifera indica \\
\hline 37. & Manggis & Garcinia mangostana \\
\hline 38. & Matoa & Pometia pinnata \\
\hline 39. & Mundu & Garcinia dulcis \\
\hline 40. & Nanas & Ananas comosus \\
\hline 41. & Palem & \\
\hline 42. & Palem raja & Cytostachis lakka \\
\hline 43. & Patah tulang & Euphorbia sp \\
\hline 44. & Pepaya & Carica papaya \\
\hline 45. & Pisang & Musa paradisiaca \\
\hline 46. & Pohon kupu-kupu & Bauhinea purpurea \\
\hline 47. & Puring & Codieaum variegatum \\
\hline 48. & Rambutan & Nephelium lappaceum \\
\hline 49. & Salak & Salaca edulis \\
\hline 50. & Sawo kecik & Manilkara kauki \\
\hline 51. & Sentul/Kecapi & Sandoricum koetjape \\
\hline 52. & Singkong & Mnihot esculenta \\
\hline 53. & Sirsak & Annona muricata \\
\hline 54. & Sirsak & Annona muricata \\
\hline 55. & Talas & Colocasia esculenta \\
\hline 56. & Tangkil & Gnetum gnemon \\
\hline 57. & Wanyi/kemang & Mangifera caesa \\
\hline
\end{tabular}




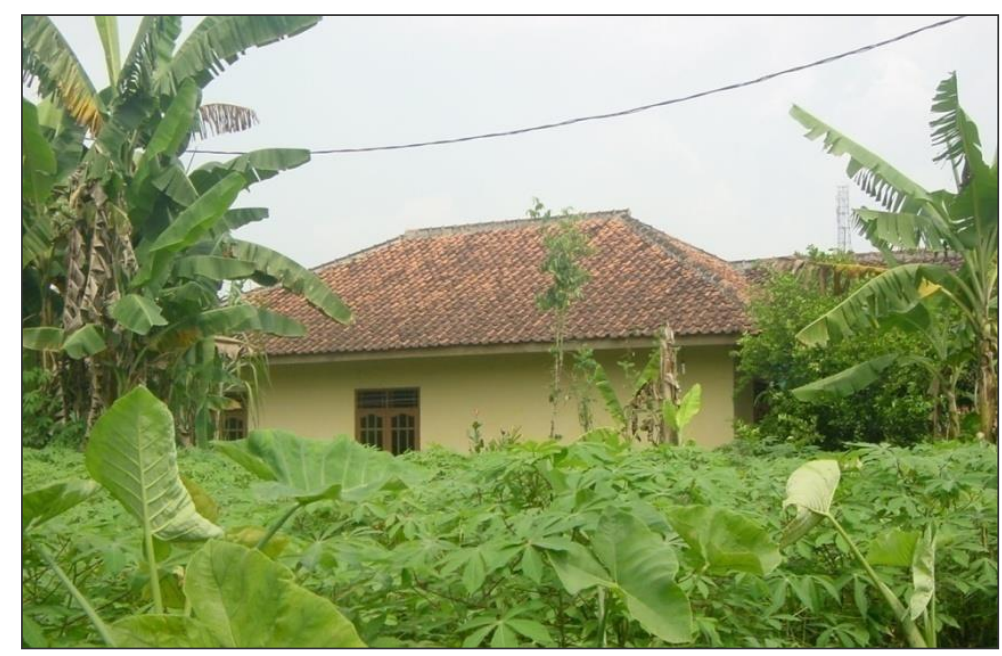

Gambar 2. Contoh pekarangan di desa Jampang, Bogor (dataran rendah)

Di Desa Cisarua terdapat 58 jenis tanaman di pekarangan (Tabel 2). Contoh lahan pekarangan di desa Cisarua ditunjukan pada Gambar 3.

Tabel 2. Jenis tanaman di pekarangan daerah dataran tinggi desa Cisarua, Bogor

\begin{tabular}{|c|c|c|}
\hline No & Nama Lokal & Nama ilmiah \\
\hline 1. & Alpukat & Persea americana \\
\hline 2. & Bambu hitam & Gigantochloa atroviolacea \\
\hline 3. & Bambu kuning & Schizostachyum brachycladum \\
\hline 4. & Bawang daun & Allium fistulosum \\
\hline 5. & Belimbing & Averrhoa carambola \\
\hline 6. & Beringin & Ficus benyamina \\
\hline 7. & Bugenvil & Bougainvillea spectabilis \\
\hline 8. & Bunga terompet & Mandevilla sanderi \\
\hline 9. & Cabe rawit & Capsicum fructecens \\
\hline 10. & Cemara & Casuarina junghuniana \\
\hline 11. & Cempaka gondok & Talauma condollii \\
\hline 12. & Cengkih & Syzygium aromaticum \\
\hline 13. & Delima & Punica granatum \\
\hline 14. & Hanjuang & Cordyline fruticosa \\
\hline 15. & Jagung & Zea mays \\
\hline 16. & Jambu biji & Psidium guajava \\
\hline 17. & Jeruk besar & Citrus maxima \\
\hline 18. & Kacang panjang & Vigna sinensis \\
\hline 19. & Kaktus raksasa & \\
\hline 20. & Kamboja & Plumeria alba \\
\hline 21. & Kamboja jepang & Adenium sp \\
\hline 22. & Kayumanis & Cinnamomum burmannii \\
\hline 23. & Kecubung & Datura metel \\
\hline 24. & Kelapa & Cocos nucifera \\
\hline 25. & Kersen & Muntingia carambola \\
\hline 26. & Labu siam & Sechium edule \\
\hline 27. & Lantana & Lantana camara \\
\hline
\end{tabular}


D Priadi; Konservasi Lekat Lahan Tanaman Pekarangan Di Dua Desa Kabupaten Bogor..

\begin{tabular}{|c|c|c|}
\hline No & Nama Lokal & Nama ilmiah \\
\hline 28. & Lengkeng & Euphoria longan \\
\hline 29. & Lumut & \\
\hline 30. & Mangga & Mangifera indica \\
\hline 31. & Markisa & Passiflora edulis \\
\hline 32. & Matoa & Pometia pinnata \\
\hline 33. & Mimba & Melia azedarach \\
\hline 34. & Mundu & Garcinia dulcis \\
\hline 35. & Nangka & Artocarpus heterophyllus \\
\hline 36. & Nenas & Ananas comosus \\
\hline 38. & Pakis haji & Cycas rumphii \\
\hline 39. & Palem putri & Veitchia merillii \\
\hline 40. & Palem raja & Roystonea alata \\
\hline 41. & Pepaya & Carica papaya \\
\hline 42. & Petai & Parkia javanica \\
\hline 43. & Pinang & Areca catechu \\
\hline 44. & Pisang & Musa paradisiaca \\
\hline 45. & Pringgodani & \\
\hline 46. & Rambutan & Nephelium lappaceum \\
\hline 47. & Sapu tangan & Maniltoa grandiflora \\
\hline 48. & Sawo duren & Chrysophillum cainito \\
\hline 49. & Sawo besar & Achras zapota \\
\hline 50. & Singkong & Manihot esculenta \\
\hline 51. & Sirih & Piper betle \\
\hline 52. & Sirsak & Annona muricata \\
\hline 53. & Srikaya & Annona squamosa \\
\hline 54. & Talas & Colocasia esculenta \\
\hline 55. & Tangkil & Gnetum gnemon \\
\hline 56. & Tebu & Saccharum officinarum \\
\hline 57. & Terung belanda & Cyphomandra betacea \\
\hline 58. & Ubi jalar & Ipomoea batatas \\
\hline
\end{tabular}

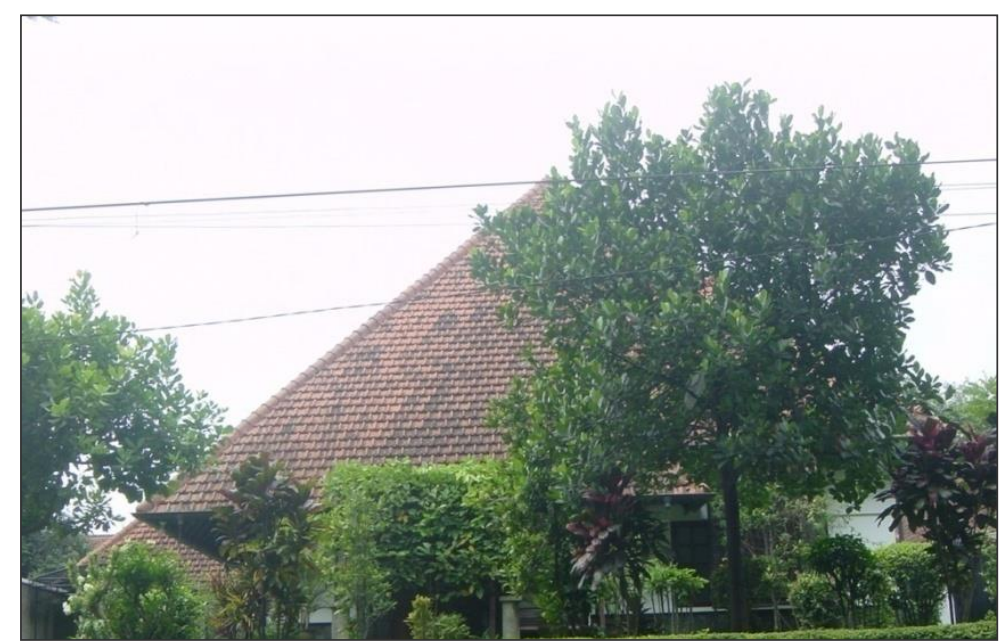

Gambar 3. Contoh pekarangan sebagai lahan petani didesa Cisarua (dataran tinggi) 


\subsection{Pembahasan}

a. Persentase kategori tanaman

Hasil pengamatan menunjukkan bahwa tanaman pekarangan yang paling banyak ditanam di Jampang adalah buah-buahan $(52,6 \%)$ sedangkan di Cisarua adalah tanaman hias (34,5\%). Cisarua termasuk daerah pariwisata Puncak, sehingga tanaman hias mendominasi tanaman pekarangan untuk dijual di kawasan Puncak (Gambar 4).

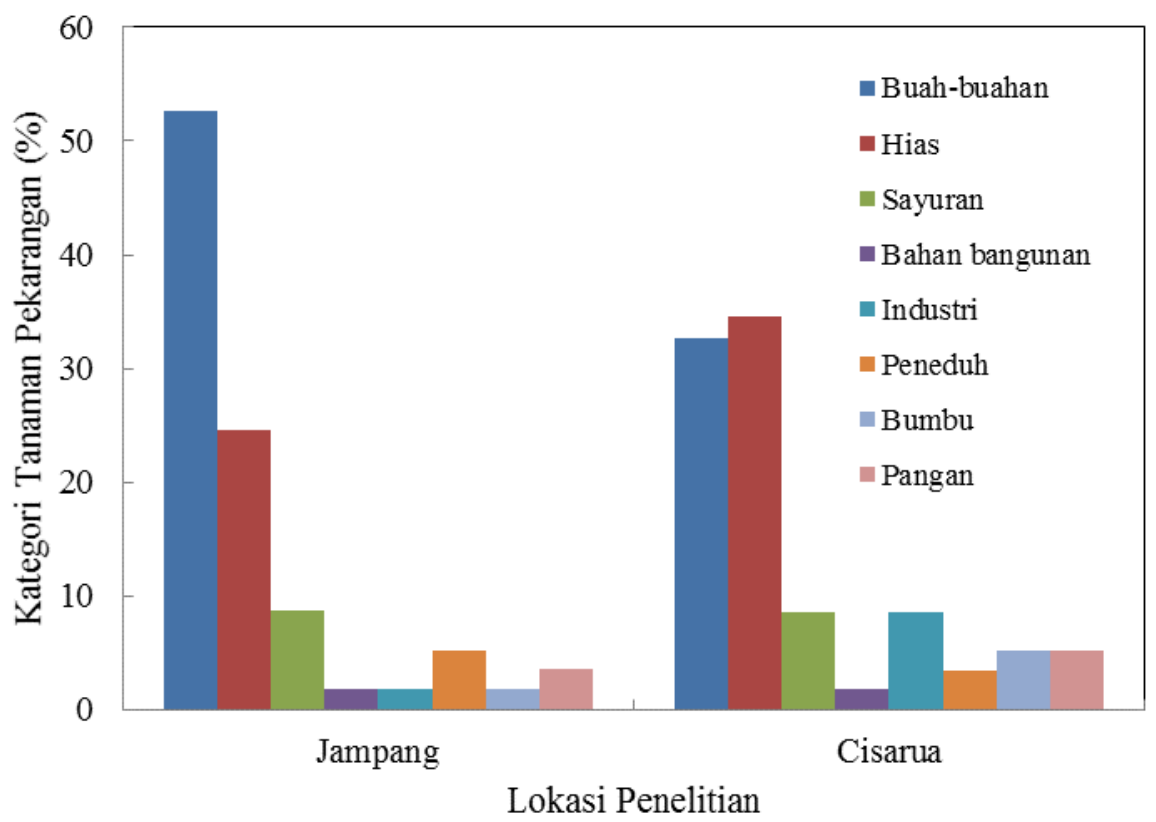

Gambar 4. Persentase kategori tanaman pekarangan di Desa Jampang dan Cisarua Kabupaten Bogor

b. Luas pekarangan

Luas pekarangan di desa Jampang relatif lebih sempit dibandingkan dengan Cisarua. Di desa tersebut batas pagar tidak jelas dan pada umumnya dipagari dengan tanaman (pagar hidup) dan permukaan tanahnya datar dan tidak bergelombang. Desa Cisarua mempunyai pekarangan yang lebih luas dibandingkan dengan desa Jampang dan pada umumnya dibatasi oleh pagar bukan tanaman seperti pagar yang terbuat dari tembok dan besi. Lahan pekarangannya berbentuk terasering dan air irigasi cukup tersedia. Menurut Syamsianah (1987) dalam Lakitan (1995) luas rata-rata lahan pekarangan di Bogor adalah $210 \mathrm{~m}^{2}$. Makin sempit luas pekarangan maka tanaman yang dibudidayakan pun keanekaragamannya makin rendah. Apabila dalam satu pekarangan terdapat lebih dari satu rumah, maka kesempatan untuk berbudidaya tanamanpun makin sedikit. Dalam konteks konservasi hal ini merupakan salah satu sebab terjadinya erosi genetik tanaman yaitu tanaman ditebang dan pada lahan tersebut didirikan rumah.

c. Aksesibilitas

Kedua desa tersebut dilalui oleh jalan beraspal antar propinsi. Desa Jampang dilalui oleh jalan propinsi dari Bogor (Jawa Barat) menuju Jakarta (DKI), sedangkan desa Cisarua dilalui oleh jalan propinsi dari Jakarta (DKI) menuju Bandung (Jawa Barat). Untuk menuju ke pelosok kampung di kedua desa tersebut biasanya menggunakan kendaraan ojek. Jarak dari kota Bogor ke desa Jampang kira-kira $10 \mathrm{~km}$, sedangkan untuk menuju desa Cisarua adalah $40 \mathrm{~km}$.

d. Agro-ekosistem

Berdasarkan tipe agro-ekosistem lahan pertaniannya dapat dibedakan menjadi pekarangan, sawah dan ladang. Pekarangan (buruan, bahasa Sunda) adalah sebidang lahan darat baik lahan kering maupun 
lahan basah yang jelas batas-batasnya dan terletak di lingkungan pemukiman, yang dapat dimanfaatan untuk budidaya tanaman pangan dan peternakan, dimana masing-masing komoditas ini mempunyai hubungan fungsional dengan penghuni rumah baik secara ekonomi maupun biofisik atau sosio kultural (Hardono, 1992). Hal ini sangat erat kaitannya dengan program diversifikasi makanan dan gizi (Adjid, 1994). Pekarangan sebagai tapak pelestarian lekat lahan untuk tanaman, sedangkan ladang adalah suatu lahan kering yang biasanya tidak jauh dari tempat tinggal yang digunakan untuk tanaman tahunan saja. Sawah adalah lahan pertanian dengan irigasi untuk bertanam tanaman semusim (kurang lebih 3 bulan).

Lahan pertanian yang digunakan untuk pelestarian lekat lahan di kedua desa tersebut adalah pekarangan, tegalan dan sawah. Keaneragaman jenis tanaman di kedua desa tersebut ditunjukkan pada Tabel 1 dan 2.

e. Cara berbudidaya tanaman

Pola tanam yang dianut oleh kedua desa tersebut adalah pola tanam campuran dimana tanaman bertahunan dicampur dengan tanaman lainnya di dalam lahan (pekarangan) yang sama sehingga di pekarangan tersebut terdapat variasi jenis tanaman. Masyarakat di kedua desa tersebut telah mengadoppsi teknologi dan sudah mengenal pupuk dan insektisida untuk memberantas hama/penyakit yang timbul dan merusak pertanamannya. Hanya tanaman-tanaman yang dianggap berpotensi ekonomis saja yang dipupuk dan diberantas hama/penyakitnya. Pupuk yang digunakan adalah pupuk organaik (kompos) dan pupuk kimia (urea, TSP maupun NPK). Pupuk kompos diproduksi dari limbah hijauan dan pupuk kandang, sedangkan pupuk kimia biasanya beli di toko/kios pupuk. Sistem pertanian yang dianut adalah sistem konvensional sedangkan pemanenan masih dilakukan secara tradisional.

\section{Simpulan dan Saran}

1. Di desa Jampang terdapat 57 jenis tanaman yang dikonservasikan di lahan pekarangan secara lekat lahan, sedangkan di desa Cisarua tercatat sejumlah 58 jenis tanaman yang dikonservasikan secara lekat lahan.

2. Di desa Cisarua yang umum dibudidayakan adalah tanaman hias sesuai dengan kondisi lahannya, sedang di desa Jampang yang umum dibudidayakan adalah tanaman buah-buahan dataran rendah.

3. Keanekaragaman tanaman yang dikonservasikan secara lekat lahan di daerah dataran tinggi lebih tinggi dibandingkan dengan dataran rendah.

4. Tanaman yang dibudidayakan di pekarangan baik di dataran rendah maupun dataran tinggi pada umumnya mempunyai nilai ekonomi misalnya nangka, cempedak, duku dan jenis tanaman hias palem di desa Jampang, sedangkan di desa Cisarua adalah labu siam, bawang daun, pisang, apukat dan tanaman hias.

\section{Ucapan terimakasih}

Penelitian ini dirintis oleh Ir. Nurul Sumiasri, APU (Almarhumah) pada tahun 2010. Semoga tulisan ini bermanfaat dan menjadi salah satu amal baik untuk beliau.

\section{Daftar Pustaka}

Adjid, D. A. (1994). Kebijaksanaan swasembada dan ketahanan pangan. Dalam Prosiding Simposium Penelitian Tanaman Pangan III. Puslitbang Tanaman Pangan. Balitbang Deptan (Hal, 50-64.).

Hardono, T. (1992). Program Diversifikasi Pangan dan Gizi. Makalah disajikan dalam Seminar Peranan Penganekaragaman Pangan Dalam Rangka Meningkatkan Gizi Masyarakat. Jakarta.19-20 Oktober 1992.

Karyono, K. (1981). Struktur pekarangan di pedesaan daerah aliran sungai Citarum, Jawa Barat. Bandung, Indonesia: Universitas Padjadjaran.

Lakitan, B. (1995). Hortikultura, Teori, Budidaya dan Pasca Panen. Jakarta, Indonesia: PT. Raja Grafindo Persada. 
Perkins J. M., Semali A., Orchard P.W., \& Rachman R. (1986). An atlas of environmental and ruminant population characteristics of Java: A multivariate analysis approach. Armidale, Australia: Forage Research Project, Department of Agronomy and Soil Science, University of New England.

Raintree, J. B. (1987). The state of the art of agroforestry diagnosis and design. Agroforestry systems, 5(3), 219-250.

Sastrapradja, D. S., Adisoemarto, S., Kartawinata, K., Sastrapradja, S., \& Rifai, M. A. (1989). Keanekaragaman hayati untuk kelangsungan hidup bangsa. Bogor, Indonesia: Pusat Penelitian dan Pengembangan Bioteknologi, LIPI.

Sumiasri, N. (1992). Tumbuhan Asli Indonesia dan Pengetahuan Lokalnya di Jawa Barat. Widya Gama, 5(3), 232-238.

Sumiasri, N, \& Kusmawan, D. (2001). Konservasi Lekat Lahan Plasma Nutfah Tumbuhan di Kabupaten Purwokerto, Banyumas dan Wonosobo. Laporan. Bogor, Indonesia: Pusat Penelitian dan Pengembangan Bioteknologi, LIPI.

Sumiasri, N., \& Priadi, D. (2003). Teknologi Konservasi Lekat Lahan Plasma Nutfah Tumbuhan Lahan Kering Timor Barat. Jurnal Penelitian Universitas Muhammadiyah Jakarta, 9(3), 345-358. 